\title{
Controlled Synthesis of a Novel Heteropolymetallic Complex with Selectively Incorporated Lanthanide(III) Ions
}

\author{
Elke Debroye, ${ }^{\dagger}$ Matthias Ceulemans, ${ }^{\dagger}$ Luce Vander Elst, ${ }^{\ddagger}$ Sophie Laurent, ${ }^{\ddagger}$ Robert N. Muller, ${ }^{\ddagger}, \S$
} and Tatjana N. Parac-Vogt*,†

\author{
${ }^{\dagger}$ Department of Chemistry, KULeuven, Celestijnenlaan 200F, 3001 Leuven, Belgium \\ ${ }^{\ddagger}$ Department of General, Organic and Biomedical Chemistry, University of Mons, Place du Parc 23, 7000 Mons, Belgium \\ ${ }^{\S}$ Center for Microscopy and Molecular Imaging (CMMI), 6041 Gosselies, Belgium
}

\section{Supporting Information}

ABSTRACT: A novel synthetic strategy toward a heteropolymetallic lanthanide complex with selectively incorporated gadolinium and europium ions is outlined. Luminescence and relaxometric measurements suggest possible applications in bimodal (magnetic resonance/ optical) imaging.

$\mathrm{L}$ anthanide chelates are gaining growing interest in the field of $\checkmark$ molecular imaging. Gadolinium complexes have a widespread application as magnetic resonance imaging (MRI) contrast agents because they enhance the longitudinal relaxation rate of water protons. ${ }^{1}$ Furthermore, numerous lanthanide compounds are used as luminescent probes in the visible and near-IR (NIR) regions for bioassay and live-cell microscopy. ${ }^{2}$ The luminescent chelates provide the advantage of long-lived luminescence but require the insertion of an aromatic chromophore into the ligand structure to sensitize lanthanide emission via energy transfer. ${ }^{3}$ The chelating moieties most commonly exist as diethylenetriaminepentaacetic acid (DTPA) or 1,4,7,10-tetraazacyclododecane-1,4,7,10-tetraacetic acid. The ligands not only prevent the toxicity effect of aqueous lanthanide ions but also minimize the nonradiative deactivation of lanthanide luminescence due to coupled $\mathrm{O}-\mathrm{H}$ vibrations.

The design of lanthanide-based systems with potential applications in bimodal imaging attracts much attention. Several heteropolymetallic complexes combining gadolinium ions and luminescent transition-metal ions have been developed and investigated. ${ }^{4}$ Mixtures of complexes in which the ligand is coordinated to paramagnetic gadolinium(III) or lanthanide ions emitting in the visible ${ }^{5}$ or NIR region ${ }^{6}$ have been intensively studied for their magnetic resonance/optical abilities. Alternatively, heterometallic complexes in which the antenna links the chelating units bearing different luminescent lanthanide ions have been reported. ${ }^{7}$ The aryl function can also be integrated into one of the structures in order to achieve a dual imaging probe. ${ }^{8}$ However, the controlled site-selective synthesis of heterometallic lanthanide complexes remains a challenge because of the very similar coordination behavior across the lanthanide series. ${ }^{3}$

This work reports a novel synthetic strategy in order to selectively incorporate two different lanthanide ions into a heterotetrametallic complex, $(\mathrm{GdL})_{3} \mathrm{Eu}$, containing three gadolinium(III) ions providing MRI response and one
europium(III) ion for the luminescent properties (Figure 1). DTPA has been chosen as the gadolinium(III) chelating unit and

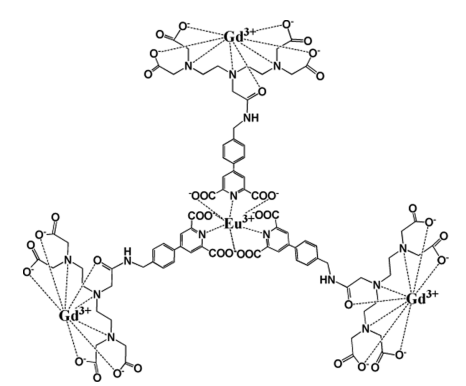

Figure 1. Schematic representation of the compound $(\mathrm{GdL})_{3} \mathrm{Eu}$.

is linked to a europium(III) chelate consisting of a parasubstituted pyridine-2,6-dicarboxylate derivative via an amide bond. In the envisioned complex, water molecules are able to approach the paramagnetic entity in order to achieve efficient relaxation enhancement, while water is excluded from the first coordination sphere of europium(III) resulting in a bright emissive compound. Furthermore, the sensitivity difference between optical and MRI is encountered by assembling three paramagnetic components around one luminescent metal ion.

The synthesis of the europium coordinating part starts with the Suzuki-Miyaura coupling of $t$-Boc-protected 4(aminomethyl)phenylboronic acid pinacol ester (1) to dimethyl 4-bromo-2,6-pyridinedicarboxylate (2), resulting in the protected dipicolinate derivative 3 (Scheme 1). The $t$-Boc group is selectively removed using trifluoroacetic acid in dichloromethane in order to attach the aromatic chromophore via an amide bond to DTPA/tert-butyl ester 4 . The tert-butyl esters of the ligand precursor $\mathbf{5}$ are selectively cleaved by stirring the product in an aqueous $\mathrm{HCl}$ solution, leading to the octadentate ligand 6 , which forms the gadolinium complex Gd6 upon reaction with gadolinium(III) chloride. Cleavage of the methyl esters is done under alkaline conditions, and the reaction of $3 \mathrm{~mol}$ equiv of the resulting GdL with europium(III) chloride yields the final metallostar compound (GdL) ${ }_{3}$ Eu.

The ${ }^{1} \mathrm{H}$ NMR spectrum of the corresponding lanthanum complex La6 displays shifting and splitting of the proton

Received: October 21, 2013

Published: January 10, 2014 
Scheme 1. Synthesis of the (GdL) ${ }_{3}$ Eu Metallostar
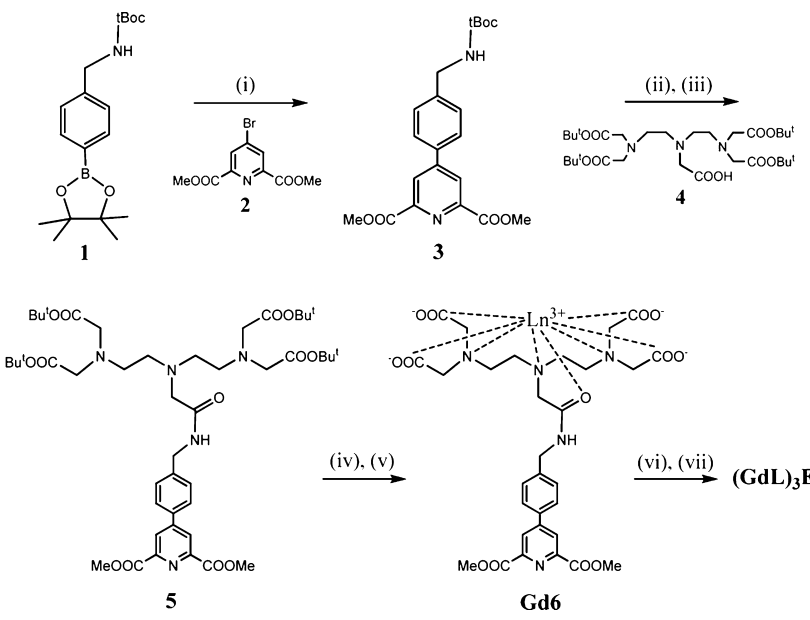

$(\mathrm{GdL})_{3} \mathrm{Eu}$

resonances in the aliphatic region, consistent with the occurrence of several interconverting isomers. After cleavage of the methyl esters, ${ }^{1} \mathrm{H}$ NMR of $\mathbf{L a L}$ reveals controlled deprotection without affecting the metal-ion coordination. Formation of the metallostar $(\mathbf{L a L})_{3} \mathbf{E u}$ leads to broadening of all signals and separation of the proton resonances in the aromatic region due to the assembly of dipicolinate units around the paramagnetic europium ion (see the Supporting Information, SI).

The absorbance spectrum of the GdL complex displays a welldefined absorption band with a maximum at $282 \mathrm{~nm}(\varepsilon=4250$ $\mathrm{cm}^{-1} \mathrm{M}^{-1}$ ) corresponding to the well-known $\pi \rightarrow \pi^{*}$ transitions of dipicolinate-based ligands ${ }^{9}$ and a shoulder at $221 \mathrm{~nm}$. The selfassembly of three dipicolinate moieties around europium resulted in a similarly shaped absorbance spectrum with a 2 $\mathrm{nm}$ red shift of the maxima and a slight decrease of the extinction coefficient per ligand of $13 \%\left(\varepsilon_{284}=11000 \mathrm{~cm}^{-1} \mathrm{M}^{-1}\right)$. The molar absorption coefficient for $(\mathbf{G d L})_{3} \mathbf{E u}$ is slightly lower compared to the one for the parent $\mathrm{Eu}^{\mathrm{III}} \mathrm{dpa}^{2-}$ tris-chelate $\left(\varepsilon_{271}=\right.$ $\left.16560 \mathrm{~cm}^{-1} \mathrm{M}^{-1}\right){ }^{10}$ Excitation into the benzyldipicolinate chromophore of $(\mathrm{GdL})_{3} \mathrm{Eu}$ at $290 \mathrm{~nm}$ gives rise to a characteristic red europium-centered emission spectrum (Figure 2). Normally, for europium(III) dipicolinate complexes, the ${ }^{5} D_{0}$

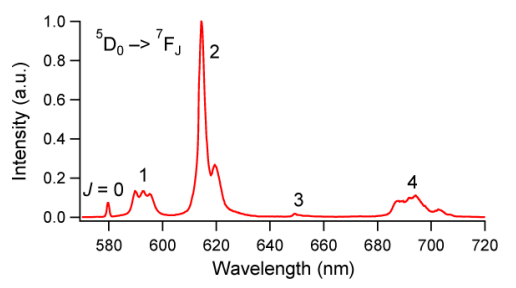

Figure 2. Corrected and normalized emission spectrum of $(\mathrm{GdL})_{3} \mathrm{Eu}$ $\left(\lambda_{\text {exc }}=290 \mathrm{~nm}\right)$ at $298 \mathrm{~K}\left(2 \times 10^{-5} \mathrm{M}\right.$ in $\left.0.1 \mathrm{M} \mathrm{NaCl}, \mathrm{pH} 7.4\right)$.

$\rightarrow{ }^{7} \mathrm{~F}_{1}$ transition is split into two bands. ${ }^{10}$ In the case of the metallostar compound, the observed unsymmetrical splitting into three bands indicates a slightly distorted $D_{3}$ symmetry, suggesting the absence of time-averaged rotational symmetry. ${ }^{11}$ In addition, the integrated emission intensity of the ${ }^{5} \mathrm{D}_{0} \rightarrow{ }^{7} \mathrm{~F}_{2}$ transition is approximately 5-6 times that of the ${ }^{5} \mathrm{D}_{0} \rightarrow{ }^{7} \mathrm{~F}_{1}$ transition, which is consistent with other para-substituted europium(III) dipicolinate complexes. ${ }^{9,12}$ It is certain that europium(III) did not replace the gadolinum(III) coordinated to the DTPA scaffold because the studied EuL complex displays a very different crystal-field splitting typical for acyclic poly- (aminocarboxylate) chelates with characteristic relative intensity values $^{5 b}$ (see the SI).

Luminescence decay of the metallostar assembly in water displays a biexponential curve, yielding lifetimes of $1.12 \pm 0.02$ and $0.23 \pm 0.03 \mathrm{~ms}$. These findings indicate the presence of more than one europium(III) species in solution, suggesting that an equilibrium between $(\mathbf{G d L})_{3} \mathbf{E u}$ and $(\mathbf{G d L})_{2} \mathbf{E u}$ has been established under the low concentrations for the luminescence measurements. ${ }^{10 \mathrm{~b}}$ The observed lifetimes for the $1: 3$ and 1:2 species are somewhat lower than those reported for other europium(III) dipicolinate complexes, 1.64 and $0.31 \mathrm{~ms}$, respectively. ${ }^{10 \mathrm{~b}}$ The mean lifetimes obtained by singleexponential analysis in both $\mathrm{H}_{2} \mathrm{O}(0.81 \pm 0.02 \mathrm{~ms})$ and $\mathrm{D}_{2} \mathrm{O}$ $(2.60 \pm 0.05 \mathrm{~ms})$ reveal a $q$ value of $0.59 \pm 0.1$. The hydration number of $\sim 0.6$ would imply a ratio of $80: 20$ between the $1: 3$ and 1:2 Eu-to-GdL species because three water molecules replace one ligand in the inner coordination sphere. Because the stoichiometry of the metallostar is critical for the photophysical properties, the stability of the complex has been further explored by monitoring the europium emission intensity and the absorbance efficiency in a $0.1 \mathrm{M}$ Tris buffer at $\mathrm{pH} 7.4$ as a function of the Eu-to-GdL ratio (see the SI). It can be seen that the strongest luminescence is obtained in the region where 0.33 equiv of europium(III) have been added and the 1:3 complex has been formed. At that time, no nonradiative quenching by coordinated water molecules takes place. Adding extra equivalents of europium(III) leads to the increased appearance of $1: 2$ and $1: 1$ assemblies having poor luminescence. Factor analysis indeed reveals the presence of three species, and the data can be satisfactorily fitted according to the proposed model, resulting in $\log \beta_{11}=6.5(2), \log \beta_{12}=12.8(2)$, and $\log \beta_{13}=$ 17.9(3). These values are slightly lower compared to other parasubstituted europium(III) dipicolinate complexes, ${ }^{9}$ but the stability is remarkably high considering the bulky substituents with a net negative charge at the pyridine 4 position. ${ }^{11 \mathrm{~b}}$ The photophysically determined species distribution is in good agreement with the one calculated with the program HySS making use of the obtained stability constants (see the SI).

The europium(III) luminescence quantum yield determined upon ligand excitation equals $9.8 \%$. Considering the observed and calculated radiative lifetimes, the intrinsic quantum yield has been estimated to be $22 \%$, resulting in a sensitization efficiency $\eta_{\text {sens }}$ of $47 \%$. These values are somewhat lower compared to those of the parent dpa ${ }^{2-}$ tris-chelate with $Q_{\mathrm{Eu}}=24 \%$ and $\eta_{\text {sens }}=61 \%$ but are in agreement with those of similar complexes reported in the literature. 9,13

Figure 3 depicts the ${ }^{1} \mathrm{H}$ NMRD profiles of $\mathbf{G d L}$ and $(\mathbf{G d L})_{3} \mathbf{E u}$ representing enhancement of the water proton relaxivity $\left(r_{1}\right)$ per $1 \mathrm{mM}$ gadolinium(III) as a function of the magnetic field strength. The profile of $(\mathbf{G d L})_{3} \mathbf{E u}$ displays a characteristic hump

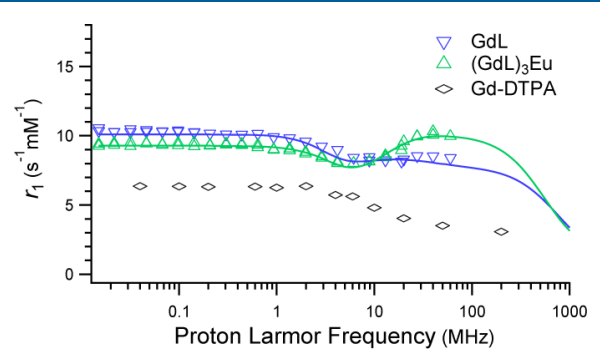

Figure 3. ${ }^{1} \mathrm{H}$ NMRD profiles of $\mathrm{GdL}$ and $(\mathrm{GdL})_{3} \mathrm{Eu}$ compared to GdDTPA in water at $\mathrm{pH} 7.4$ and $310 \mathrm{~K}$. The lines represent the fitted data. 
between 20 and $100 \mathrm{MHz}$, which is assigned to the formation of a supramolecular structure. At $20 \mathrm{MHz}$ and $310 \mathrm{~K}$, the relaxivity is enhanced to $8.3 \mathrm{~s}^{-1} \mathrm{mM}^{-1}$ for GdL and $9.6 \mathrm{~s}^{-1} \mathrm{mM}^{-1}$ for (GdL) ${ }_{3}$ Eu with respect to $3.8 \mathrm{~s}^{-1} \mathrm{mM}^{-1}$ for Gd-DTPA, as could be expected given the higher molecular weight of the synthesized chelates. Taking into account the presence of three gadolinium ions per metallostar compound, a longitudinal relaxation rate of $28.8 \mathrm{~s}^{-1} \mathrm{mM}^{-1}$ per molecule is obtained at $20 \mathrm{MHz}$. During the theoretical fitting of the NMRD data, the inner- and outer-sphere contributions to the paramagnetic relaxivity were taken into account and the resulting parameters are listed in Table 1. Mainly

Table 1. Parameters Obtained by Fitting the ${ }^{1} \mathrm{H}$ NMRD Data in Water at $\mathrm{pH} 7.4$ and $310 \mathrm{~K}$

$\begin{array}{lcrr} & \text { Gd-DTPA } & \text { GdL }^{a} & (\mathbf{G d L})_{3} \mathbf{E u}^{a} \\ \tau_{\mathrm{R}}(\mathrm{ps}) & 54 \pm 1 & 225 \pm 4 & 314 \pm 5 \\ \tau_{\mathrm{S} 0}(\mathrm{ps}) & 87 \pm 3 & 112 \pm 1 & 82 \pm 1 \\ \tau_{\mathrm{V}}(\mathrm{ps}) & 25 \pm 3 & 42 \pm 2 & 30 \pm 1\end{array}$

${ }^{a}$ Fixed values: $q=1, r=0.31 \mathrm{~nm}, d=0.36 \mathrm{~nm}, \tau_{\mathrm{M}}=300 \mathrm{~ns}$, and $D=$ $3.3 \times 10^{-9} \mathrm{~m}^{2} \mathrm{~s}^{-1}$. $^{14}$

the longer rotational correlation time $\tau_{\mathrm{R}}$ is responsible for the beneficially high relaxation rates. In the case of GdL, the possible formation of intermolecular hydrogen bonds can lead to an apparent increased molecular weight, improving the relaxivity.

In conclusion, the sequential deprotection of a newly designed ditopic ligand allows the site-selective coordination of lanthanide ions, leading to a unique heteropolymetallic lanthanide complex, $(\mathbf{G d L})_{3} \mathbf{E u}$, which can be considered as a potential bimodal MRI/ visible imaging agent. At the center of the metallostar, the europium(III) ion is barely subjected to nonradiative deactivation by coordinated $\mathrm{OH}$ oscillators, achieving bright-red luminescence with a quantum yield up to $10 \%$. Furthermore, enhanced longitudinal relaxation rates up to $31 \mathrm{~s}^{-1} \mathrm{mM}^{-1}$ per molecule at $40 \mathrm{MHz}$ were obtained because of the presence of three gadolinium ions at the periphery of the compound able to coordinate one water molecule each. The possibility of making a central macrocyclic ligand in order to avoid dissociation to the $(\mathrm{GdL})_{2} \mathrm{Eu}$ species has been considered for future work. In general, the presented synthetic route offers broader applications because it allows the insertion of different pairs of lanthanide ions for further investigation of dual-optical or magnetic resonance/ optical imaging abilities.

\section{ASSOCIATED CONTENT}

\section{(S Supporting Information}

Details on instrumentation and methods and synthetic procedures and characterization of ligand and complexes. This material is available free of charge via the Internet at http://pubs. acs.org.

\section{AUTHOR INFORMATION}

\section{Corresponding Author}

*E-mail: tatjana.vogt@chem.kuleuven.be.

Notes

The authors declare no competing financial interest.

\section{ACKNOWLEDGMENTS}

E.D. and T.N.P.-V. acknowledge the IWT Flanders and FWO Flanders (Grant G.0412.09) for financial support. L.V.E., S.L., and R.N.M. are thankful for the ARC Programs, the FNRS,
BELSPO, and COST Actions (D38 and TD1004), and the EMIL Program.

\section{REFERENCES}

(1) Caravan, P.; Ellison, J. J.; McMurry, T. J.; Lauffer, R. B. Chem. Rev. 1999, 99, 2293.

(2) Bünzli, J.-C. G. Chem. Rev. 2010, 110, 2729.

(3) Parker, D. Chem. Soc. Rev. 2004, 33, 156.

(4) (a) Dehaen, G.; Eliseeva, S. V.; Kimpe, K.; Laurent, S.; Vander Elst, L.; Muller, R. N.; Dehaen, W.; Binnemans, K.; Parac-Vogt, T. N. Chem.-Eur. J. 2012, 18, 293. (b) Debroye, E.; Dehaen, G.; Eliseeva, S. V.; Laurent, S.; Vander Elst, L.; Muller, R. N.; Binnemans, K.; ParacVogt, T. N. Dalton Trans. 2012, 41, 10549. (c) Koullourou, T.; Natrajan, L.; Bhavsar, H.; Pope, S. J. A.; Feng, J.; Kauppinen, R.; Narvainen, J.; Shaw, R.; Scales, E.; Kenwright, A.; Faulkner, S. J. Am. Chem. Soc. 2008, 130, 2178.

(5) (a) Placidi, M. P.; Engelmann, J.; Natrajan, L. S.; Logothetis, N. K.; Angelovski, G. Chem. Commun. 2011, 47, 11534. (b) Debroye, E.; Eliseeva, S. V.; Laurent, S.; Vander Elst, L.; Petoud, S.; Muller, R. N.; Parac-Vogt, T. N. Eur. J. Inorg. Chem. 2013, 2013, 2629.

(6) (a) Tallec, G.; Fries, P. H.; Imbert, D.; Mazzanti, M. Inorg. Chem. 2011, 50, 7943. (b) Bonnet, C. S.; Buron, F.; Caillé, F.; Shade, C. M.; Drahoš, B.; Pellegatti, L.; Zhang, J.; Villette, S.; Helm, L.; Pichon, C.; Suzenet, F.; Petoud, S.; Tóth, E. Chem.-Eur. J. 2012, 18, 1419.

(7) (a) Placidi, M. P.; Villaraza, A. J. L.; Natrajan, L. S.; Sykes, D.; Kenwright, A. M.; Faulkner, S. J. Am. Chem. Soc. 2009, 131, 9916. (b) Sorensen, T. J.; Tropiano, M.; Blackburn, O. A.; Tilney, J. A.; Kenwright, A. M.; Faulkner, S. Chem. Commun. 2013, 49, 783.

(8) (a) Mamedov, I.; Parac-Vogt, T. N.; Logothetis, N. K.; Angelovski, G. Dalton Trans. 2010, 39, 5721. (b) Jones, J. E.; Amoroso, A. J.; Dorin, I. M.; Parigi, G.; Ward, B. D.; Buurma, N. J.; Pope, S. J. A. Chem. Commun. 2011, 47, 3374.

(9) Gassner, A.-L.; Duhot, C. 1.; Bünzli, J.-C. G.; Chauvin, A.-S. Inorg. Chem. 2008, 47, 7802.

(10) (a) Moore, E. G. Dalton Trans. 2012, 41, 5272. (b) Chauvin, A.-S.; Gumy, F.; Imbert, D.; Bünzli, J.-C. G. Spectrosc. Lett. 2004, 37, 517.

(11) (a) Bünzli, J.-C.; Eliseeva, S. In Lanthanide Luminescence; Hänninen, P., Härmä, H., Eds.; Springer: Berlin, 2011; Vol. 7, p 1. (b) Platas-Iglesias, C.; Piguet, C.; Andre, N.; Bunzli, J.-C. G. J. Chem. Soc., Dalton Trans. 2001, 3084.

(12) George, M. R.; Golden, C. A.; Grossel, M. C.; Curry, R. J. Inorg. Chem. 2006, 45, 1739.

(13) Andres, J.; Chauvin, A.-S. Eur. J. Inorg. Chem. 2010, 2010, 2700.

(14) Vander Elst, L.; Sessoye, A.; Laurent, S.; Muller, R. N. Helv. Chim. Acta 2005, 88, 574. 